\title{
Retraction Note to: UI design of visual communication of coastal city landscape based on embedded network system and remote sensing data
}

\section{Qian Xie ${ }^{1}$}

Published online: 25 November 2021

(c) Saudi Society for Geosciences 2021

Retraction Note to: Arabian Journal of Geosciences (2021) 14: 1052 https://doi.org/10.1007/s12517-021-07167-3

The Editor-in-Chief and the Publisher have retracted this article because the content of this article is nonsensical. The peer review process was not carried out in accordance with the Publisher's peer review policy. The author disagrees with this retraction.

The original article can be found online at https://doi.org/10.1007/ s12517-021-07167-3.

\section{Qian Xie}

xq891116@163.com

1 School of Digital Media and Art Design, Nanyang Institute of Technology, Nanyang 473000, Henan Province, China 